\title{
Position-specific activity of the Hox1.1 promoter in transgenic mice
}

\author{
ANDREAS W. PÜSCHEL, RUDI BALLING and PETER GRUSS \\ Max-Planck-Institut ful biophysikalische Chemie, Abteilung Molekulare Zellbiologie, Am Fassberg, D-3400 Gortingen, FRG
}

\section{Summary}

During development, positional values have to be assigned to groups of cells. The murine Hox genes are a class of genes that are predicted to be involved at some stage in this process. During embryogenesis they are expressed in distinct overlapping region- and stagespecific patterns and therefore must be regulated in response to positional information. In this study, we have analysed the activity of Hoxl.1 promoter sequences in transgenic mice. The use of lac $Z$ as a marker allows a detailed analysis of expression at the single cell level during early embryonic development. We show that $3.6 \mathrm{kbp}$ of promoter and $1.7 \mathrm{kbp}$ of $3^{\prime}$ sequences provide sufficient regulatory information to express a transgene in a spatial and temporal manner indistinguishable from the endogenous Hoxl.1 gene during the period of development when Hox1.1 expression is established. The activation occurs in a strict order in specific ectodermal and mesodermal domains. Within each of these domains the transgene is activated over a period of four hours apparently randomly in single cells. In a following second period, Hox1.1 and transgene expression patterns diverge. In this period, transgene expression persists in many mesodermally derived cells that do not express Hox 1.1 indicating the absence of a negative regulatory element in the transgene. The anterior boundary of transgene expression is identical to that of Hox1.1. However, no posterior boundary of transgene expression is set, suggesting that a separate element absent from the transgene specifies this boundary.

Key words: gastrulation, homeo-box, lacZ, pattern formation, transgenic mice.

\section{Introduction}

Trying to understand how an organism develops is to ask how patterns are established and elaborated during development. It is generally assumed that the physical basis for pattern formation is the precise spatial and temporal regulation of gene expression.

The fruitfly Drosophila melanogaster is, at the moment, the best characterised multicellular organism with respect to the genetic and molecular basis of pattern formation (Akam, 1987; Ingham, 1988). Isolation and analyses of developmental genes from Drosophila led to the identification of several conserved sequence elements coding for distinct protein domains (for reviews see: Gehring and Hiromi, 1986; Dressler and Gruss, 1988). One of these is the homeo-box, which is found in many genes in Drosophila involved in the specification of positional information. Subsequent to their identification in the fly, homeo-boxes have been found in many organisms as diverse as Caenorhabditis elegans (Way and Chalfie, 1988; Costa et al. 1988) and Homo sapiens (Boncinelli et al. 1988 and references therein). At least 30 different homeo-box containing genes (Hox genes) have been isolated from the mouse genome (for reviews see: Martin et al. 1987; Dressler and Gruss, 1988; Dressler, 1989). The Hox genes are expressed in complex overlapping region- and stage- specific patterns during embryonal development (Holland and Hogan, 1988). Based on their homology to Drosophila, developmental genes, such as Antennapedia or Ultrabithorax, and transcription factors, like Oct1 and Oct2 (Herr et al. 1988, and references therein), it is currently assumed that the Hox genes are sequence-specific DNA-binding transcription factors (for reviews see: Levine and Hoey, 1988; Wright et al. 1989). Ectopic expression of Hoxl.1 in transgenic mice (Balling et al. 1989) or overexpression of Xhox3 by injection of synthetic RNA into Xenopus embryos (Ruiz i Altaba and Melton, 1989) leads to specific developmental abnormalities. All evidence accumulated so far is consistent with the hypothesis that the Hox genes have a function in pattern formation or positional specification as transcriptional regulators. However, their precise role in this process remains to be determined.

Hox 1.1 is expressed from day 7.5 to day 14 of murine embryogenesis (Colberg-Poley et al. 1985). Expression is initially detectable only in the allantois (day 7.5) (Mahon et al. 1988). Subsequently the transcript appears in a specific region of the neural plate (day 8 ) and in the mesoderm (day 8.5). During organogenesis (day 9.5 to 11.5 ) expression is maintained in specific mesodermal structures and progressively turned off in others (Mahon et al. 1988; Dressler and Gruss, 1989). At day 
12 of development Hoxl.1 is expressed in two overlapping domains in neural tube, spinal ganglia and prevertebrae.

As regulation of Hox1.1 expression is dependent on positional information, a study of the regulatory elements defining the domain of expression relative to the anteroposterior axis will help to elucidate the molecular mechanism specifying positional information during murine embryogenesis. Putative Hox 1.1 promoter sequences were linked to the lac $Z$ gene and transgenic mice were generated. As a first step to unravel the mechanisms regulating pattern formation during gastrulation in the mouse, we report the partial reproduction of Hox1.1 regulation during embryogenesis in transgenic mice. The transgene was correctly regulated early in development (day 7.5-8.5) but its expression pattern diverged from that of the endogenous gene after this period. The correct expression early in development allowed a detailed analysis of the establishment of position-specific expression of a Hox gene.

\section{Materials and methods}

\section{Recombinant DNA}

A $1.7 \mathrm{kbp} P v u I I-E c o$ RI fragment isolated from pm6-12 (Colberg-Poley et al. 1985) was ligated into pSPT19 cut with $B g l \mathrm{II}$, which was blunt-ended by Klenow polymerase treatment, and EcoRI. A HindIII linker (Biolabs, 8mer) was inserted into the EcoRI site resulting in plasmid pm6 $63^{\prime}$. The $5.3 \mathrm{kbp} S a l \mathrm{I}-B g l \mathrm{II}$ fragment isolated from $\lambda \mathrm{m} 6$ was cloned into the pSPT19 vector cut with SalI and BamHI.(pm6 $\left.65^{\prime}\right)$. To obtain pm6 6 this fragment was isolated after SalI and $K p n I$ digestion and cloned into pm6 $63^{\prime}$. This procedure resulted in the deletion of a $110 \mathrm{bp} B g l \mathrm{II}-P v u \mathrm{II}$ fragment from the genomic DNA. To construct pm6lacZ1 the following fragments were linked in the indicated order: a $3.7 \mathrm{kbp}$ SalI-SacI fragment from pm6 $\Delta$, a $1 \mathrm{kbp} H$ indIII-ClaI fragment from pCH110 (Pharmacia), a $2 \mathrm{kbp} \mathrm{ClaI-BamHI} \mathrm{frag-}$ ment from pMC1871 (Pharmacia) and a $1.7 \mathrm{kbp} K p n \mathrm{I}-E c o \mathrm{RI}$ fragment from pm6 $63^{\prime}$. The vector is based on pm6 $\Delta 3^{\prime}$. The lac $Z$ coding sequences were fused to $120 \mathrm{bp}$ coding Hox 1.1 DNA that are not translated in m6lacZl because of a stop codon in the lac $Z$ fragment and $1.18 \mathrm{kbp} 3^{\prime}$ nontranslated sequences. The fusion gene was separated from the vector for embryo injections by HindIII digestion. Fragments were separated on agarose gels and isolated by electroelution. The fragment was further purified by phenol: chloroform extraction, chloroform extraction, ethanol precipitation, gel filtration over a P30-column (Biorad) and filtration through a $0.22 \mu \mathrm{m}$ filter (Schleicher and Schuell). To generate RNA probes for RNase protection assays pSPTm6Ex2 was constructed by cloning a $E c o$ RI-PstI fragment from the second Hox1.1 exon into pSPT19 (see Fig. 1). pSPTm6AP was constructed to generate ${ }^{35} \mathrm{~S}$-labelled RNA probes for in situ hybridisations. A $308 \mathrm{bp}$ AluI-PstI fragment from the first Hoxl.1 exon (Kessel et al. 1987) was cloned into PSPT19 to generate this plasmid.

\section{Generation of transgenic mice}

NMRI outbred mice and C57Bl/6/DBA/F1 mice were purchased from the Zentralinstitut für Versuchstierzucht, Hannover. Transgenic mice were produced essentially as described by Hogan et al. (1986). Six week old NMRI female mice were superovulated by injecting intraperitoneally (i.p.) $5 \mathrm{i} . \mathrm{u}$. of gonadotropin from pregnant mare serum $48 \mathrm{~h}$ prior to injecting $5 \mathrm{i}$.u. of human chorionic gonadotropin. Female mice were then mated with $\mathrm{C} 57 \mathrm{BL} / 6 / \mathrm{DBA} / \mathrm{F}_{1}$ male mice. The next day, one-cell stage embryos were flushed from the oviducts of the mated female mice with M2 medium (Hogan et al. 1986). The eggs were freed of cumulus cells by hyaluronidase treatment. The male pronuclei of the fertilized eggs were microinjected with approximately 2 picoliters of DNA at a concentration of $2 \mathrm{ng} \mathrm{ul}^{-1}$. The injected, fertilized eggs were then transferred to pseudopregnant recipient NMRI female mice. Transgenic mice were identified by Southern blot analysis of DNA extracted from mouse tail biopsies as described by Hogan et al. (1986).

\section{$R N A$ analysis}

RNase protection assays were done essentially as described (Balling et al. 1989). $50 \mu \mathrm{g}$ of total embryonic RNA was

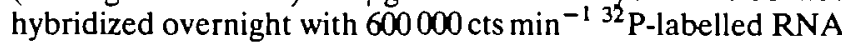
transcribed from a OxaNI-linearized pSPTm6Ex2 template at $65^{\circ} \mathrm{C}$ in $50 \%$ formamide, $400 \mathrm{~mm} \mathrm{NaCl}, 40 \mathrm{~mm}$ Pipes (pH 6.4), and $1 \mathrm{~mm}$ EDTA. The hybridisation mixture was digested for $90 \mathrm{~min}$ after addition of $350 \mu 110 \mathrm{~mm}$ Tris (pH7.5), $5 \mathrm{~mm}$ EDTA, $250 \mathrm{~mm} \mathrm{NaCl}, 50 \mu \mathrm{g} \mathrm{ml}^{-1}$ RNase A, and $150000 \mathrm{u} \mathrm{ml}^{-1} \mathrm{RNase} \mathrm{T} 1$ at $37^{\circ} \mathrm{C}$.

\section{In situ hybridisation}

In situ hybridisations were performed essentially as described previously (Dony and Gruss, 1987). pSPTm6AP was used to transcribe a ${ }^{35} \mathrm{~S}$-labelled RNA probe specific for $H o x 1.1$. The transcription reaction and purification of the probe was done as described for the RNase protection assays.

\section{$X$-Gal staining and histology}

Embryos between day 7 and 13 (the day of detection of the vaginal plug was day zero) were fixed in $1 \%$ formaldehyde, $0.2 \%$ glutaraldehyde, $0.02 \% \mathrm{NP} 40,1 \times \mathrm{PBS}$ for $30 \mathrm{~min}$ at $4^{\circ} \mathrm{C}$, followed by two washes in $1 \times$ PBS for $20 \mathrm{~min}$ at room temperature. Embryos were stained at $30^{\circ} \mathrm{C}$ in $1 \mathrm{mg} \mathrm{ml}^{-1} \mathrm{X}$ Gal, $5 \mathrm{~mm}^{\mathrm{K}} \mathrm{K}_{3} \mathrm{Fe}(\mathrm{CN})_{6}, 5 \mathrm{mM} \mathrm{K}_{4} \mathrm{Fe}(\mathrm{CN})_{6}, 2 \mathrm{~mm} \quad \mathrm{MgCl}_{2}$ $1 \times$ PBS overnight. For sectioning, stained embryos were fixed overnight in $4 \%$ formaldehyde in PBS, dehydrated and embedded in paraffin. Cryosections were air-dryed, fixed at $4^{\circ} \mathrm{C}$ for $10 \mathrm{~min}$ like whole embryos and stained overnight as described above. Staining of cryosections gave a better representation of $\beta$-galactosidase activities than staining of whole embryos. Neural tube and some parts of the prevertebrae were poorly stained in whole-mount stainings but show high $\beta$-galactosidase levels in stained cryosections. The assay is linear only over a short range of activities. Sections were incubated for different times to obtain a complete representation over the whole range of transgene activity in different tissues.

\section{Results}

\section{Identification of Hox1.1 promoter sequences}

In a first series of experiments, $7.1 \mathrm{kbp}$ of genomic DNA from the Hox1 cluster were used to generate transgenic mice (Fig. 1A). This DNA contains both exons of Hox 1.1, the intron, $3.6 \mathrm{kbp}$ of $5^{\prime}$ and $0.3 \mathrm{kbp}$ of $3^{\prime}$ nontranscribed sequences. A $110 \mathrm{bp}$ deletion was introduced into the second exon of Hoxl.1 to allow detection of transgenic RNA by a RNase protection assay. This construct $(\mathrm{m} 6 \Delta)$ was sufficient to direct 
A

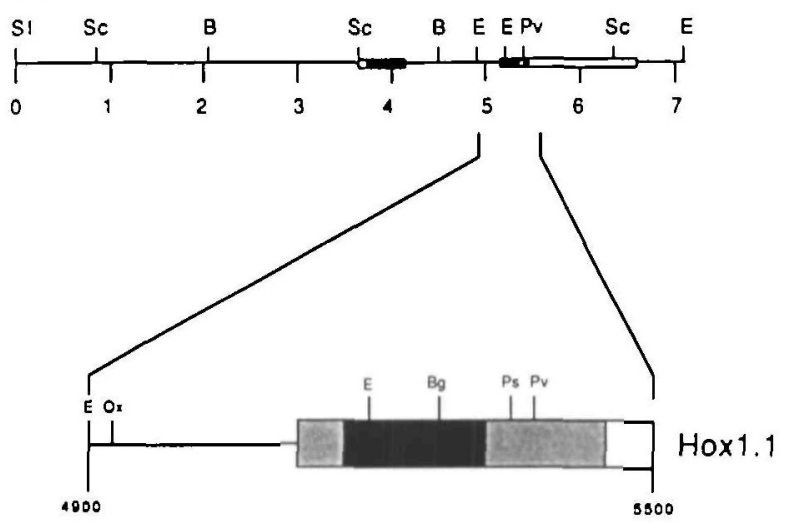

B

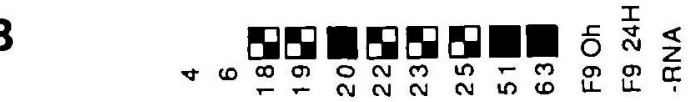

endogenous -

Hox 11

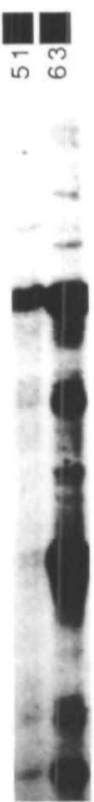

Fig. 1. Identification of Hox1.1 promoter sequences. (A) Structure of Hox 1.1 and m6 $\Delta$. In the top half a restriction map of $7.1 \mathrm{kbp}$ from the Hoxl locus used to generate m6 $\Delta$ is shown. Open boxes represent exons, stippled boxes coding sequences and black boxes the homeobox. Sizes are indicated in kbp. From this DNA a $110 \mathrm{bp} B g l \mathrm{II}-P v u \mathrm{II}$ fragment was deleted and replaced by pSPT19-polylinker sequences (see Materials and methods) as indicated in the bottom half. Broken lines represent the deletion. An EcoRI-PstI fragment cloned into pSPT19 (pSPTm6Ex2) was used to generate an antisense RNAprobe (arrow) for RNase-mapping. Black bars indicate sizes of the protected RNAs (217 nucleotides for the endogenous Hox1.1 RNA and 150 nucleotides for RNA transcribed from $\mathrm{m} 6 \Delta$ ). The abbreviations for restriction enzyme sites are: B for $B a m$ HI, Bg for BglII, E for EcoRI, Ox for OxaNI, Ps for PstI, Pv for PvuII, Sc for SacI and Sl for SalI. (B) RNasemapping of RNA from transgenic embryos. Fertilized oocytes were injected with m6 $\Delta$ and retransferred to pseudopregnant foster mothers. Embryos were recovered on day 12 of gestation. Transgenic embryos were identified by Southern blot analysis of placenta DNA. Total RNA was prepared from embryos and analysed by a RNase-protection assay using a probe transcribed from pSPTm6Ex2 (see Materials and methods). Numbers indicate the numbers of the individual embryo. As a control RNA from undifferentiated (F9 $0 \mathrm{H}$ ), differentiated F9 cells (F9 24h, differentiated with retinoic acid and cyclic AMP for 24 hours) and no RNA (-RNA) were included. Boxes indicate RNAs from transgenic embryos and the copy number relative to the endogenous Hox1.1 gene (black box: one or more copies per haploid genome, mosaic box: less than one copy per haploid genome). Protected fragments corresponding to the endogenous and the transgenic RNA are indicated. On the left hand side, an overnight exposure is shown, on the right hand side, a four day exposure of the same gel is shown. Only low amounts of RNA were recovered from embryo 51.

expression after transfection into F9 cells (A.W.P. unpublished results), which express Hox1.1 mRNA upon differentiation with retinoic acid and cyclic AMP.

Fertilized oocytes were injected and retransferred to pseudopregnant foster mothers. Embryos were analysed 12 days after retransfer (corresponding to day 12.5 of development). Of the 70 embryos obtained, $8 \mathrm{em}$ bryos were found to be transgenic by Southern blot analysis of placenta DNA. RNA extracted from 8 transgenic and 2 nontransgenic embryos was analysed by RNase-protection assays (Fig. 1B). Expression of m6 $\Delta$ was found in two transgenic embryos. One embryo (embryo 63) showed high, a second (embryo 51) only low levels of m6 transcripts. Thus 2 out of 8 transgenic embryos expressed transgenic RNA. 5 of the 8 transgenic embryos contained less than one copy of the transgene per haploid genome and were probably mosaic. This might account for the lack of expression in these embryos, since none of the mosaic embryos contained detectable amounts of transgenic RNA. As the transgene was active in two out of three embryos containing one or more transgene copies per genome, we conclude that the transgene contains sufficient information for expression during embryogenesis.

Generation of transgenic mice containing a Hox1.1.lac Z fusion gene

The $7.1 \mathrm{kbp}$ of the Hox 1 locus contain at least some cisacting elements that allow expression during embryogenesis. To analyse the spatial expression pattern, $3.6 \mathrm{kbp}$ of Hoxl.1 promoter sequences were fused to the $E$. coli lac $Z$ gene as a readily assayable marker (Fig. 2A). A poly(A) addition signal was provided by a $1.7 \mathrm{kbp}$ DNA which contains most of the second exon 
Fig. 2. Transgenic mice expressing a $H o x 1.1$ lacZ fusion gene. (B) Structure of Hox 1.1 and m6lacZ1. In the top line the structure of the fragment from the Hoxl locus used to generate m6lacZ1 is shown. See Fig. 1 for explanations. Sequences between the SacI site upstream of the Hox1.1 ATG and the $P v u I I$ site in the second exon were replaced by lac $Z$ coding sequences (crossed bar; see Materials and methods). (B-D) Transgenic embryos recovered on day 12 of gestation. (B,C) Fertilized oocytes were injected with m6lacZl and retransferred to pseudopregnant foster mothers. Embryos were recovered on day 12 of gestation, fixed and incubated with X-Gal (see Materials and methods). Embryos E4 (B) and E49 (C), which show a comparable expression pattern, are shown. (D,E) Embryos recovered from transgenic line L4 on day 12 of gestation. Transgenic lines carrying m6lac $Z 1$ as a transgene were established. Transgenic males were mated to NMRI mice and embryos recovered on day 12 of gestation, fixed and incubated with X-Gal. Embryos stained overnight at $30^{\circ} \mathrm{C}$ (D) or $4^{\circ} \mathrm{C}(\mathrm{E})$ are shown. Incubation at $4^{\circ} \mathrm{C}$ results in lower overall expression but gives a better representation of different levels of expression. (F) Summary of transgenic embryos (E4, E49 and E98) and transgenic lines (L1-L5) obtained. Mosaic embryos with very low levels of $\beta$ galactosidase activity were not included. Embryos with completely different patterns of expression compared to the prototypic pattern of L4 embryos (ectopic) or additional, ectopic, sites of expression (add. ectopic) are indicated. Fig. 3. Expression of Hox1.1 and m6lacZ1 at day 12 of gestation. Expression was analysed by in situ hybridisation of RNA probes to cryosections $(B, D, F)$, staining of cryosections of transgenic embryos $(A, C, E, G)$ or staining of whole embryos, which were afterwards embedded in paraffin and sectioned $(\mathrm{H}, \mathrm{I})$. Comparable levels of sections are shown. Except in A, left is caudal and right is rostral.
All sections are from day 12 embryos obtained from line L4. (A) Sagittal section stained with X-Gal. (B,D,F) Parasagittal sections hybridized with a Hoxl.1 specific probe. (B) Hoxl.1 is expressed in spinal ganglia.

Expression above background levels is first detectable in the Sth cervical ganglion (C5). (D,F) Hoxl.1 is expressed in neural tube (nt) and prevertebrae (pv) T3 (third thoracic prevertebra) to T13. No Hoxl.1 RNA is detectable in chondrification centres. (C,E,G) Parasagittal section stained with X-Gal. (C) m6lacZ1 is expressed in spinal ganglia. The first ganglion with detectable amounts of stain is the 5th cervical ganglion (C5; the second cervical ganglion is indicated as $C 2$ ). (E) The transgene is expressed in neural tube (nt) and prevertebrae (pv). Low level of $\beta$ galactosidase activity can be found in the third thoracic prevertebra (T3). The level in $\mathrm{T} 3$ is too low to be represented on the picture. Like in spinal ganglia expression in the most rostral expressing prevertebrae is not uniform. Single cells show higher levels of activity than most others. (G) The transgene is not expressed in chondrification centres. Transgene expression is more extensive than that of Hox1.1. (H) Frontal section. A whole day 12 embryo was incubated in staining solution, paraffinembedded and sectioned. Due to the procedure, staining is lower than in stained cryosections. Neural tube (nt) is stained poorly. Expression in neural tube and spinal ganglia (sg) is detectable starting at the level of the fifth cervical ganglion. (I) Sagittal section of a whole mount stain. Expression levels in the rostral and caudal half are different in the C7 ganglion. A similar pattern is seen in the C6 ganglion in $\mathrm{C}$. Due to the lower extent of staining in I compared to $\mathrm{C}$, this pattern is seen in the $\mathrm{C} 7$ ganglion in $\mathrm{I}$ but not in C. Shorter incubation of cryosection in staining solution, however, shows a similar division in C7 (data not shown). and $0.47 \mathrm{kbp} 3^{\prime}$ nontranscribed sequence. The $5^{\prime}$ and $3^{\prime}$ ends of m6lacZ1 were identical to $\mathrm{m} 6 \Delta$. This plasmid (m6lacZ1) showed transcriptional activity in F9 cells (A.W.P. unpublished results). For production of transgenic mice, vector sequences were removed. Fertilized oocytes were injected with m6lacZ1 and retransferred to pseudopregnant foster mothers. Embryos were recovered on day 12 of gestation by laparatomy and analysed for $\beta$-galactosidase ( $\beta$-gal) activity by incubation with 5-bromo-4-chloro-3-indolyl- $\beta$-d-galactoside (X-Gal). Transgene expression was analysed by external inspection and in serial sections of paraffin-embedded embryos. This allowed a quick test if the Hox1.1 transgene was active in transgenic embryos and if the Hox1.1 expression pattern could be fully or partially reproduced. Embryos were analysed at day 12 of gestation as at this stage Hox1.1 transcript levels peak and the expression domain is most clearly defined (Mahon et al. 1988; Dressler and Gruss, 1989; this paper). Out of a total of 118 embryos, 15 embryos showed only a few cells positive for transgene activity. Three embryos (E4,E49,E98) were obtained that strongly expressed the transgene (Fig. 2F). Since m6lacZ1 was active in transgenic embryos and the pattern was similar to that of Hox1.1 (see below), transgenic lines containing m6lacZ1 were established for a detailed analyses. 5 out of 70 live offspring were identified as transgenic by Southern blot analysis (lines L1-L5; Fig. 2F). These founder animals were crossed to NMRI mice to establish transgenic lines and produce transgenic embryos for histochemical analysis. As shown in Fig. 2F, 2 out of the 5 transgenic lines did not express the transgene (L1,L2), whereas strong $\beta$-gal activity was detected in 3 lines (L3,L4,L5). Embryos from line L4 and transgenic embryos E4 and E49 had an identical expression pattern with the exception of some ectopic expression unique to each integration site in $\mathrm{E} 4$ and $\mathrm{E} 49$ (Fig. 2B-E). The pattern of $\beta$-gal activity in L4 embryos was identical within a litter and between different litters derived from different transgenic males. Expression in day 12 embryos from lines L3 and L5 differed from the L4 pattern (data not shown) although analyses of earlier stages showed expression identical to that of L4 embryos (see below). Embryo E98 showed a completely different pattern of expression (data not shown). As the patterns of ectopic expression in E4, E49, E98 and later stages of L3 were unique to each embryo or line they probably represent influences of the integration site. Similar observations have been made for other Hox1.1 lacZ transgenes (A.W.P., R.B. and P.G., unpublished results). Transgenic embryos showing ectopic expression were not analysed in detail here and are subject of a separate report (A.W.P., R.B. and P.G., manuscript in preparation). Embryos derived 


\section{A}
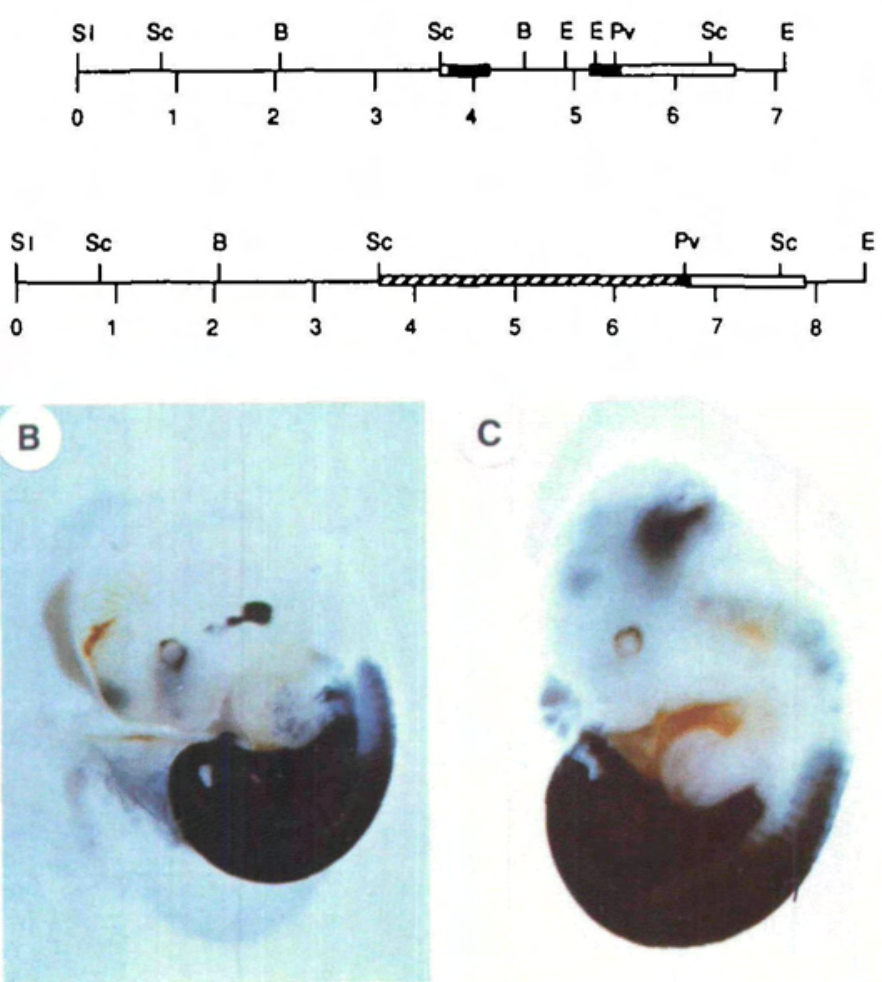

C

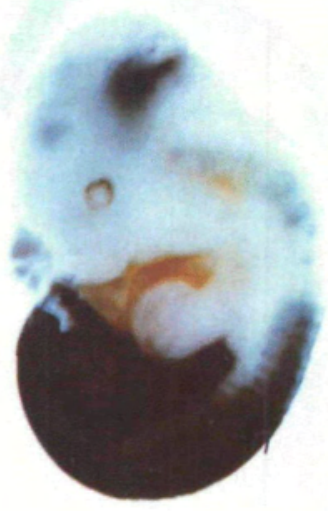
m6lacZ1

F

E4

E49

HOX1.1 E98

L1

L2

L4

L5

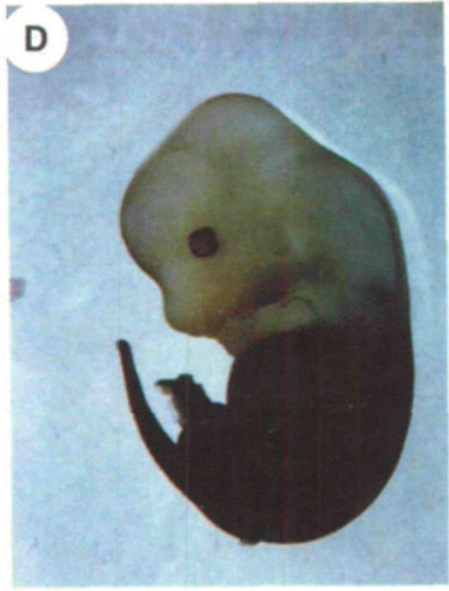

$+$

$+$

$+$
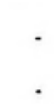

.

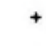

$+$
Expression

$+$

$+$

E

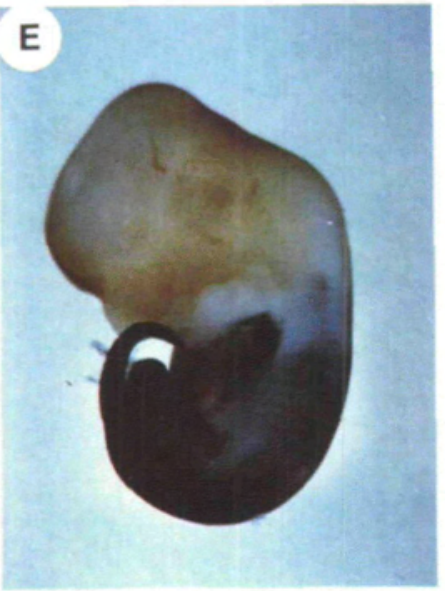

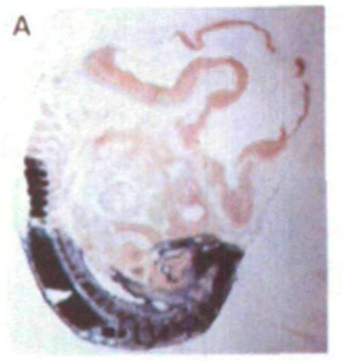
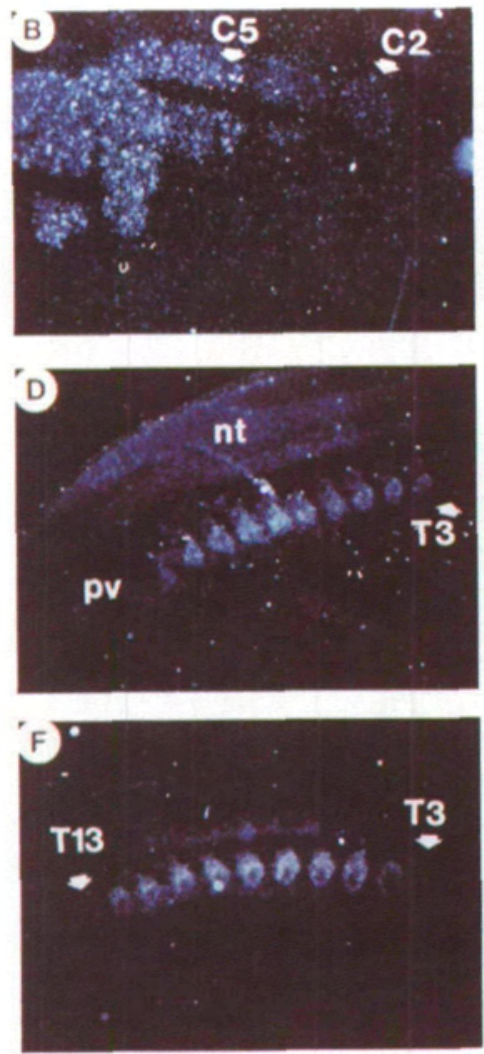
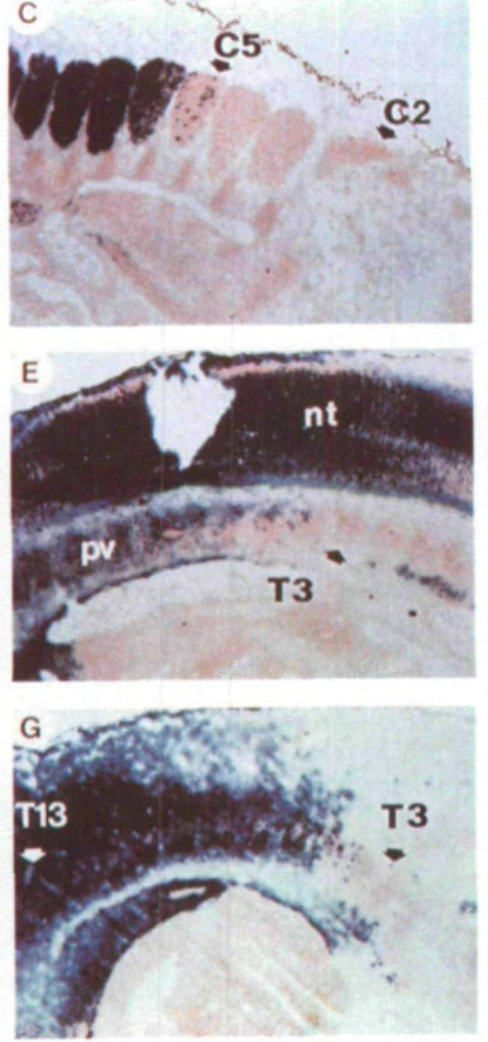
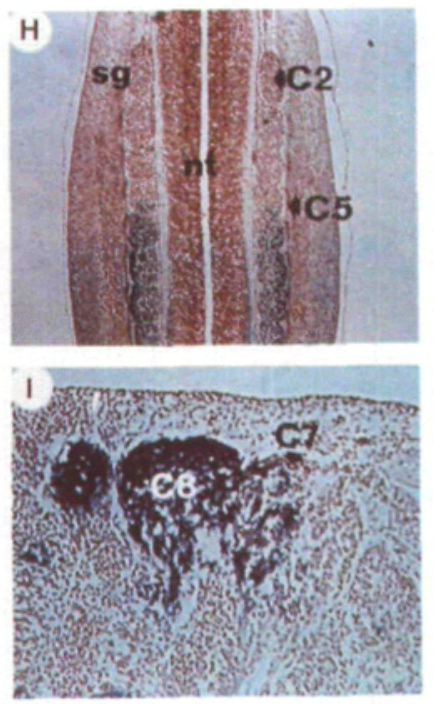

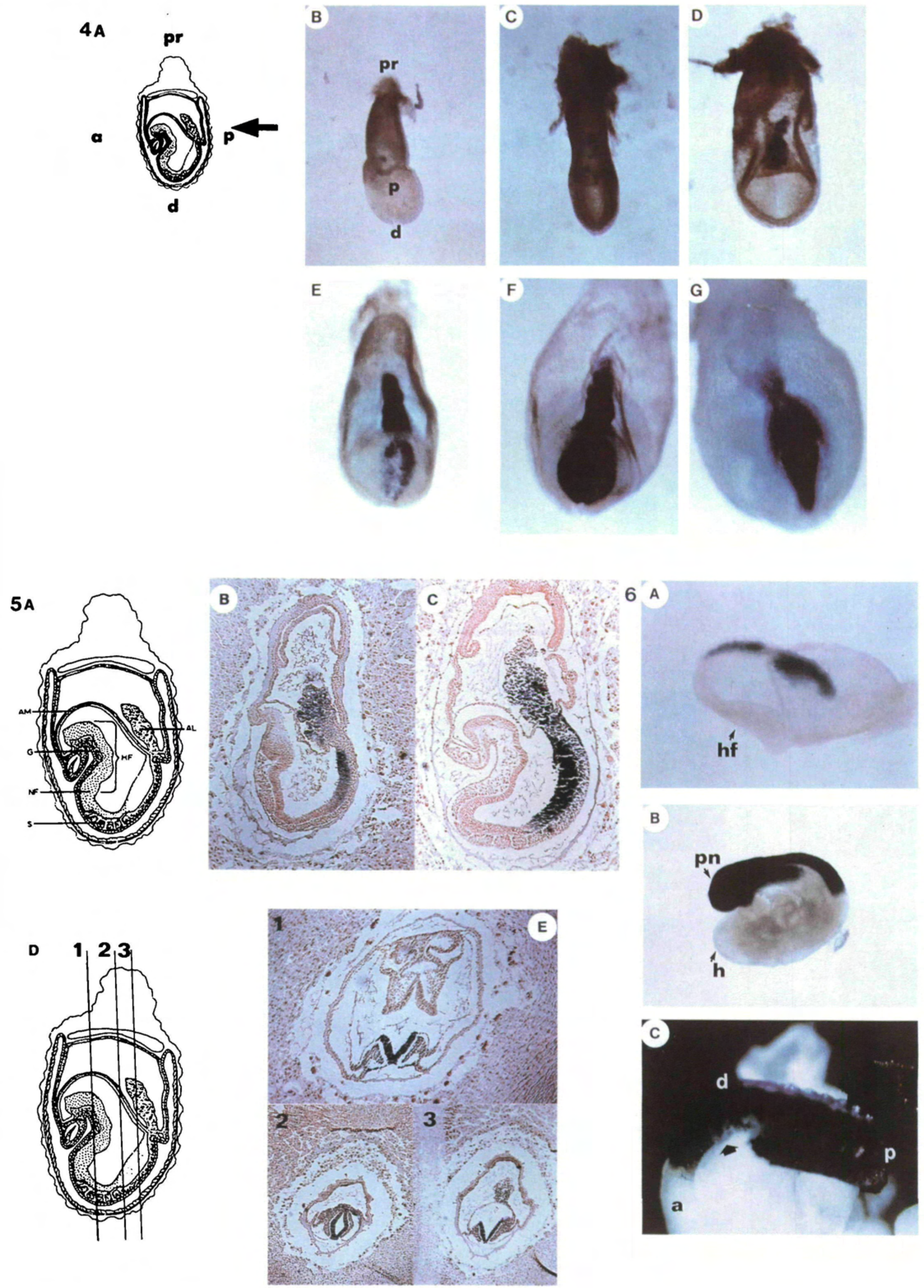
Fig. 4. Activation of transgene expression between day 7.5 and 8.5. Transgenic males were mated to NMRI mice in two hour intervals and embryos recovered at the indicated days of gestation and processed as described in Fig. 2. (A) Schematic representation of a day 8.5 embryo. The arrow indicates the direction of view in all pictures. Abbreviations are: a, anterior; $p$, posterior; pr, proximal; d, distal. Embryos were recovered at the following approximate times after detection of the vaginal plug; 7 days and 16 hours (B), 7 days and 18 hours (C), 7 days and 20 hours (D), 7 days and 22 hours (E), 8 days (F), 8.5 days (G).

Fig. 5. Expression of m6lacZ1 in transgenic day 8 embryos. Embryos derived from line L4 were recovered on day 8.0 (B) or day $8.5(\mathrm{C}, \mathrm{E})$ of gestation including the decidua, fixed, stained with X-Gal, embedded in paraffin and sectioned. (A) Schematic representation of a day 8.5 embryo. Abbreviations are: AL, allantois; AM, amnion; G, foregut; $\mathrm{HF}$, head fold; NF, neural fold; S, somite. (B) Sagittal section of a day 8.0 embryo. High amounts of stain are seen in allantois and neural plate. (C) Sagittal section of a day 8.5 embryo. High levels of transgene activity are detectable in allantois and neural plate, low levels in unsegmented mesoderm in the posteriormost quarter. A similar pattern was observed in stained cryosections. (D) Schematic representation of a day 8.5 embryo. Levels of sections in (E) are indicated $(1,2,3)$. (E) Different levels of cross section through a day 8.5 embryo. Transgene activity can be detected in all three germ layers.

Fig. 6. Transgene expression between day 8 and 9 . (A) Lateral view of a day 8.0 L4 embryo. (B) Lateral view of a day 9.5 L4 embryo. (C) Lateral view of a day 9.5 L4 embryo. The arrow points at presumptive migrating neural crest cells visible in somites not expressing m6lacZ1. Abbreviations are: $a$, anterior; $d$, dorsal; $h$, head; hf, headfold; $p$, posterior; $p n$, posterior neuropore.

from line L5 showed a patchy expression on day 12 (data not shown). The reason for this is unclear.

\section{Hox1.1 and transgene have identical anterior boundaries of expression}

The Hox1.1 expression pattern in day 12 embryos was determined by in situ hybridisation of cryosections with RNA probes and compared to sections of stained transgenic embryos. In addition, embryos from line L4 were analysed by staining of serial cryosections. Hybridisation with a Hox1.1-specific probe showed high RNA levels extending from the 3rd to the 13th thoracic prevertebrae (Fig. 3D,F). Somewhat lower expression was seen in neural tube (Fig. 3D) and spinal ganglia posterior to the fourth cervical ganglion (Fig. 3B). Expression within this domain was not uniform. It increased gradually over prevertebrae $\mathrm{T} 3$ and T4 and decreased over T11 to T13. Expression in ganglia was first detectable above background levels in the fifth cervical ganglion and increased to maximal levels in the sixth cervical ganglion (Fig. 3B).

Analysis of serial sections from all transgenic embryos showed that the anterior boundary of transgene expression was the same as that of Hoxl.1 (Fig. $3 C, E, G, H)$. The intensity of staining was not uniform along the first three ganglions. Similar to Hoxl.1 a gradient of increasing transgene activity could be seen (Fig. 3B). Within the ganglia $\mathrm{C} 5$ and $\mathrm{C} 6$, few cells showed high levels of $\beta$-gal activity in a background of cells with low or no detectable staining. A similar observation was made for the endogenous Hoxl.1 gene (Fig. 3B). There was a marked difference in intensity of staining between the caudal and the rostral halves of the C6 and C7 ganglion (Fig. 3C,I, and data not shown). This difference probably reflects the origins of the neural crest cells that gave rise to these ganglia (see Discussion). A gradient of increasing transgene activity was also seen in prevertebrae (Fig. 3E,G). In prevertebrae and rib primordia, both Hoxl.1 and the transgene were not active in the centres of chondrification (Fig. 3F,G). Many characteristics of Hox1.1 expression therefore were reproduced by the transgene.

On day 12 the domain of transgene expression is extended relative to Hox1.1

In marked contrast to Hox1.1, there was no posterior limit of transgene expression. Staining extended uniformly to the posterior end of the day 12 embryo (Fig. 3A). Within this domain transgene expression was not limited to prevertebrae, ganglia and neural tube. High levels of stain could be found in epidermis, connective tissue and some myotome derivatives (Fig. 3A,G). These tissues do not contain detectable levels of endogenous Hox1.1 RNA (Fig. 3F; Mahon $e t$ al. 1988; Dressler and Gruss, 1989) and therefore represent ectopic sites of transgene expression.

In summary, the transgene was expressed during embryogenesis in a specific region of the body. The expression domain of m6lacZ1 was colinear at the anterior boundary with Hoxl.1 but not restricted at the posterior end. Expression was extended not only posteriorly but also to many mesodermally derived cells. Hoxl.1 is initially expressed in a broad region of the embryo and expression is progressively shut off in most mesodermal tissues (Mahon et al. 1988). This process might not take place for m6lacZ1 resulting in widespread transgene expression. To test this possibility transgene expression in early stages of development was analysed.

\section{Transgene expression is activated and expressed} identical to Hox1.1 at early stages of development

Line L4 was chosen for an extensive analysis of transgene expression at various stages of development. NMRI mice were mated to transgenic males and embryos dissected out at different stages of development, fixed and incubated with a staining solution containing X-Gal. Timed matings yielded 100 transgenic embryos at approximately two hour intervals between day 7.5 p.c. and day 8.5 p.c. Embryos younger than 7.5 days were not analysed.

Transgene expression was activated in a strict temporal and spatial order in embryonal tissues. Expression was first detectable on day 7.5 to 7.75 (Fig. 4B) in the allantois. Expressing cells appeared at the tip of the allantoic bud and subsequently increased continuously in number in the following two to four hours 
exclusively in the allantois (Fig. 4C,D). The first stained cells in the embryo appeared in the neuroectoderm when already all cells in the allantois expressed m6lacZ1 (day 7.8) (Fig. 4E).

During the following approximately 2 to 4 hours of development, the number of stained cells in the neuroectoderm increased continuously (Figs 4E,F, $5 B, C, E)$. Activation within this region apparently occurs randomly in individual cells. No obvious regular pattern of activation within a germ layer is detectable during this period. Cells positive for lac $Z$ were confined to an area in the posterior part of the embryo (Fig. 5C). Serial sections showed a higher amount of stain in the posterior part of the neural plate (Fig. 5B,C). Thus, as has been observed for the Hoxl.1 and Hoxl.3 genes (Dressler and Gruss, 1989), expression at early stages was strongest at the caudal end of the embryo and decreases cranially. At day 8.0 p.c. all cells within a defined region of the neural plate expressed the transgene (Figs 4F, 6A). Starting at day 8.0, the transgene was activated in mesodermal cells (day 8.0 to 8.5 ) (Fig. 4G). As observed in allantois and neuroectoderm activity spread from posterior to anterior, the anterior border of expression initially being diffuse in contrast to the very defined border from day 9.5 on (Figs 4G, 6B). The apparent anteroposterior movement of transgene expression reflects the growth of the mesoderm by addition of cells to the presomitic mesoderm. Serial sections showed that all three germ layers, ecto- mesoand endoderm, were positive for lac $Z$ expression at day 8.5 (Fig. 5C). The pattern and time course of transgene activation coincides with that of Hoxl.1 as far as it has been described (Mahon et al. 1988; Dressler and Gruss, 1989). The early pattern of lac $Z$ expression described for L4 was identical to that found in embryos of the lines L 3 and L5 (data not shown). Therefore, the early developmental regulation of $\mathrm{mblacZ} 1$ in the embryos described was due to the cis-acting sequences present in the transgene and not the result of the integration sites.

\section{After day 8.5, Hox1.1 and transgene expression diverge}

At day 8.5 m6lacZ1 expression was established in a specific region of the embryonic body. In the following 5 days of development expression was maintained in most tissues derived from mesodermal and ectodermal cells within this region.

Starting at day 8.5 p.c. expression in the allantois was diminishing (Fig. 4G). After closure of the anterior neuropore, expression was detectable at day 9.5 in neural tube, epidermal ectoderm and all mesodermal tissues in a region extending from the level about 6 to 7 somites posterior to the anterior border of m6lacZ1 expression in neural tube to the posterior end of the embryo (Fig. 6B). In the region of this offset of expression between neural tube and somites, some stained cells are visible within or between adjacent somites (Fig. 6C). Presumably these are migrating neural crest cells that will give rise to the spinal and sympathetic ganglia developing at these positions.

Between day 10.5 p.c. and day 12.5 p.c. the pattern and the boundaries of m6lacZ1 activity do not change (data not shown).

\section{Discussion}

Region-specific expression during embryogenesis is the most conspicuous feature of mammalian Hox genes and, together with their homology to developmental genes in Drosophila, is evidence for a potential function in the specification of positional information along the anterior-posterior axis. Independent of a functional characterisation, these genes permit analysis of gene regulation depending on positional information.

To identify sequences responsive to positional cues, Hox 1.1 promoter sequences were linked to a marker gene, the $E$. coli lac $Z$ gene, and its spatiotemporal expression pattern analysed in transgenic mice. Using $3.6 \mathrm{kbp}$ Hox1.1 promoter sequences and $1.7 \mathrm{kbp}$ Hox $1.13^{\prime}$ sequences, we obtained transgenic mice that showed lac $Z$ expression in a specific region of the embryo. The ease and high resolution of $\beta$-galactosidase detection allowed a more precise analysis than previously possible by in situ hybridisation. As the expression pattern of the transgene was identical to that of the endogenous gene early in development it was possible to analyse the establishment of the pattern in detail.

Regulation of Hox1.1 expression occurs in two phases The activation of m6lacZ1 parallels the endogenous Hox1.1 gene in a strict temporal and spatial manner early during development. Beginning at day $7.5 \mathrm{lacZ}$ expression is first detectable in the allantois and subsequently in neural ectoderm. Activation in embryonic mesoderm is both delayed and more posterior along the body axis. Expression in presomitic mesoderm is first detectable when the cells corresponding to the first somites expressing Hox 1.1 are added to the presomitic mesoderm. The subsequent expansion of expressing mesodermal cells reflects the growth of the mesoderm by recruitment of cells first from the primitive streak and later from the tail bud. A different observation has been made for one other Hox-gene. The Xenopus $X I H b o x 1$ gene is initially expressed in a narrow band in ectoderm and mesoderm sharing the same anterior and posterior boundaries (De Robertis et al. 1989). Subsequent morphogenetic movements, however, lead to an offset of expression between mesoderm and neural tube. Based on the early expression pattern of $X I H$. boxl, homeogenetic induction across germ layer boundaries (De Robertis et al. 1989) was proposed as a mechanism to account for the precise alignment of expression in different germ layers. Although Hox 1.1 is not a paralog of $X I H b a x 1$, it is possible to conclude that the proposed mechanism can not be a general one. At least, our data exclude this model for the murine Hox1.1 gene.

m6lacZ1 and Hox1.1 are regulated in parallel early in development during the period when expression is established (day 7.5 to 8.5 ). Expression patterns di- 
verge, however, when within this region Hox1.1 expression becomes restricted. Although the anterior boundary of m6lacZ1 expression (5th cervical ganglion and 3rd thoracic prevertebrae) is identical to that of Hox1.1, there is, in contrast to Hox1.1, no posterior boundary. In addition, in marked contrast to Hoxl.1, expression is not restricted to a subset of mesodermally derived tissues, the sclerotomes. Thus the second regulatory process is not executed by m6lacZ1. Some aspects of this later regulatory process, however, are executed, since the transgene, like Hox1.1, is not expressed in the chondrification centres of prevertebrae. The Hox1.1 sequences present in m6lacZ1 are not sufficient to specify all aspects of Hox1.1 expression. Sequences further $5^{\prime}$ or $3^{\prime}$ or internal sequences like the intron removed to construct m6lacZ1 could contain this information. Peak levels of expression in each germ layer are initially found in the posterior part of the expressing domain (days 8.5 to 9.5 ) but shift anteriorly later during development (day 12.5).

A highly specific activity has also been reported for Hox1.3 promoter sequences (Zakany et al. 1988). However the spatial and temporal profile of this pattern does not correlate with the described distribution of Hox1.3 mRNA (Dony and Gruss, 1987; Dressler and Gruss, 1989). The Hox1.3/lacZ transgene is expressed in only a small subset of cells expressing Hox1.3. In addition transgene activity is first detectable at day 11 , about four days later than Hoxl.3 is first expressed. It has still to be determined if this difference reflects different mechanisms of position-specific regulation or if the Hoxl.3 element regulates just one aspect of the late expression pattern of Hox1.3 (days 11 to 13).

\section{Hox1.1 expression as a positional marker in neuroectoderm}

Hox 1.1 and the transgene m6lacZ1 are expressed at day 8.5 in a specific region of the neural plate. The neural crest cells originating from this region will form spinal ganglia expressing Hoxl.1 (Mahon et al. 1988) and m6lacZ1 later during development. In day 9.5 embryos these neural crest cells are readily detectable by X-Gal staining. The differential expression of m6lacZl in neural crest cells along the anteroposterior axis indicates that the migrating neural crest cells must have acquired position-dependent properties. It is not clear, however, if these properties are stable or if they can be changed by interacting with a different cellular environment. Once spinal ganglia are formed, some ganglia (C6 and $\mathrm{C7}$ ) show nonuniform transgene activity in anterior and posterior halves. In the chick, a single spinal ganglion arises from the neural crest cells originating from two somitic levels (Teillet $\mathrm{et}$ al. 1987). Thus different populations of neural crest cells seem to contribute to the halves of the ganglion also in the mouse.

The limits of Hoxl.1 expression in Fig. 3 differ slightly (by one segment) from a previous report (Mahon et al. 1988) which sets the anterior boundary at the 4th cervical ganglion. We do not know the reason for this difference. One possibility is that the C2 ganglion has been mistaken for the $\mathrm{C} 1$ ganglion, which degenerates at day 11 of development (Dawes, 1930). This agrees with our observations as we have not detected a ganglion between the $\mathrm{C} 2$ ganglion and Froriep's ganglion in three serial sectioned day 12 embryos (Fig. 3H and data not shown).

\section{Conclusions}

The identification of position-responsive promoter sequences not only enables dissection of the responsible cis-acting elements but also, by the use of lac $Z$ as a marker, allows detailed analyses of the establishment and development of the specified pattern. Analysis of the development of the m6lacZ1 expression pattern compared to Hoxl.1 suggests that at least two phases of regulation can be distinguished. In the period from day 7.5 to 8.5 , the initial pattern is established. Modifying this pattern, the final distribution of the gene product is obtained by selective persistance of expression in specific subpopulations of cells. The identification of regulatory elements necessary for this process will uncover the molecular mechanisms defining regions of Hox1.1 expression along the anterior-posterior axis.

The authors would like to thank Merve Olowson and Kirsten Schaub for excellent technical assistance. We thank all members of the lab and especially Gregory Dressler and Martyn Goulding for constructive comments on the manuscript. This work was supported by the Max-Planck Gesellschaft.

\section{References}

AKAM, M. (1987). The molecular basis for metameric pattern in the Drosophila embryo. Development 101, 1-22.

Balling, R., Mutter, G., Gruss, P. and Kessel, M. (1989). Craniofacial abnormalities induced by ectopic expression of the homeobox gene Hox 1.1 in transgenic mice. Cell 58, 337-347.

Boncinelli, E., Somma, R., Acampora, D., Pannese, M., D'Esposito, M., Faiella, A. And Simeone, A. (1988).

Organization of human homeobox genes. Human Reproduction $3,880-886$.

Colgerg-Poley, A. M., Voss, S. D., Chowdhury, K., Stewart, C. L. AND Gruss, P. (1985). Clustered homeo boxes are differentially expressed during murine development. Cell 43, $39-45$.

Costa, M., Weir, M., Coulson, A., Sulston, J. and Kenyon, C. (1988). Posterior pattern formation in C. elegans involves position-specific expression of a gene containing a homeobox. Cell 55, 747-756.

DAwES, B. (1930). The development of the vertebral column in mammals, as illustrated by its development in Mus musculus. Phil. Trans. R. Soc. Lond. B 218, 115-117.

De Robertis, E., Oliver, G. and Wright, C. V. E. (1989). Determination of axial polarity in the vertebrate embryo: homeodomain proteins and homeogenetic induction. Cell 57, 189-191.

Dony, C. AND Gruss, P. (1987). Specific expression of the Hox 1.3 homeo box gene in murine embryonic structures originating from or induced by the mesoderm. EMBO J. 6, 2965-2975.

Dressler, G. R. AND Gruss, P. (1988). Do multigene families regulate vertebrate development? Trends in Genetics 4, 214-219.

Dressler, G. R. (1988). An update on the vertebrate homeobox. Trends in Genetics 5, 129-130.

Dressler, G. R. and Gruss, P. (1989). Anterior boundaries of Hox gene expression in mesoderm derived structures correlate with the linear gene order along the chromosome.

Differentiation, in press. 
Gehring, W. J. And Hiromi, Y. (1986). Homeotic genes and the homeobox. Ann. Rev. Genet. 20, 147-173.

Herr, W., Sturm, R. A., Clerc, R. G., Corcoran, L. M., Baltimore, D., Sharp, P. A., Ingraham, H. A., Rosenfeld, M. G., Finney, M., Ruvkun, G. and Horvitz, H. R. (1988). The Pou domain: a large conserved region in the mammalian pit-1, oct-1, oct-2, and Caenorhabditis elegans unc-86 gene products. Genes \& Development 2, 1513-1516.

Hogan, B., Constantini, F. and LacY, E. (1986). Manipulating the mouse embryo. Cold Spring Harbor Laboratory.

Holland, P. W. H. and Hogan, B. (1988). Expression of homeo box genes during mouse development: a review. Genes \& Development 2, 773-782.

INGHAM, P. W. (1988). The molecular genetics of embryonic pattern formation in Drosophila. Nature, Lond. 335, 25-34.

Kessel, M., Schulze, F., Fibi, M. And Gruss, P. (1987). Primary structure and nuclear localization of a murine homeodomain protein. Proc. nain. Acad. Sci. U.S.A. 84, 5306-5310.

LeVIne, M. And HoeY, T. (1988). Homeobox proteins as sequencespecific transcription factors. Cell 55, 537-540.

Mahon, K. A., Westphal, H. and Gruss, P. (1988). Expression of homeobox gene Hoxl.1 during mouse embryogenesis. Development 104 (Suppl.), 187-195.

Martin, G. R., Boncinelli, E., Duboule, D., Gruss, P.,
Jackson, I., Krumlauf, K., Lonal, P., McGinnis, W., Ruddle, F. AND WOHLGEMUTH, D. (1987). Nomenclature for homeoboxcontaining genes. Nature, Lond. 325, 21-22.

Ruiz i Altaba, A. ANd Melton, D. (1989). Involvement of the Xenopus homeobox gene Xhox 3 in pattern formation along the anterior-posterior axis. Cell 57, 317-326.

Teillet, M.-A., Kalcheim, C. and Le Douarin, N. M. (1987). Formation of the dorsal root ganglia in the avian embryo: segmental origin and migratory behavior of neural crest progenitor cells. Devl Biol. 120, 329-347.

WAY, J. C. AND ChalFie, M. (1988). mec-3, a homeobox-containing gene that specifies differentiation of the touch receptor neurons in C. elegans. Cell 54, 5-16.

Wright, C. V. E., Cho, K. W. Y., Oliver, G. and De Robertis, E. M. (1989). Vertebrate homeodomain proteins: families of region-specific transcription factors. Trends in Biochem. Sci. 14, $52-56$.

Zakany, J., Tuggle, C. K., Patel, M. D. and Nguyen-Huu, M C. (1988). Spatial regulation of homeobox gene fusions in the embryonic central nervous system of transgenic mice. Neuron I, $679-691$. 